\title{
Tokluk İndeksi Ölçümünde Kullanılan, EFNARC ve Yuvarlak Plaka Eğilme Deney Yöntemlerinin Karşılaştırılması
}

\author{
Gökhan KÜLEKÇİ* \\ Gümüşhane Üniversitesi, Mühendislik ve Doğa Bilimleri Fakültesi, Maden Mühendisliği Bölümü, 29100 Gümüşhane, \\ Türkiye \\ *Sorumlu Yazar/Corresponding Author \\ Derleme Makalesi/Review Article \\ E-mail: gokhankulekci@gmail.com \\ Geliş Tarihi/Received: 20.09.2021 \\ Orcid ID:0000-0002-2971-4045 \\ Kabul Tarihi/Accepted: 26.10.2021
}

\section{ÖZET}

Özellikle madencilik ve inşaat sektöründe sıkça kullanılan püskürtme beton boru hattı aracılığıyla basınçlı hava ile iletilen agrega, çimento, su ve bazı kimyasal katkı maddelerinden oluşan ve püskürtme yoluyla yapılan beton olarak tanımlanır. Tahkimat gerektirmeden hızlı bir şekilde uygulanabildiği, istenilen şekilde şekillendirilebildiği ve her türlü yüzeye uygulanabildiği için yeraltı mühendisliği inşaatları, kaya ve zemin desteği, yapıların kaplama ve onarımı gibi birçok alanda yaygın olarak kullanılmaktadır. Bu avantajlarına ek olarak, beton içerisinde farklı miktar ve yapıda lif kolaylıkla katıla bilinir. Gelişen teknoloji ile betonda lif kullanımı artmıştır. Lif kullanımının temel nedeni enerji sönümleme özelliğidir. Tokluk olarak da isimlendirilen, yük-sehim eğrisinin altında kalan alanı ile ifade eden bu özellik, malzemenin mekanik (Çatlak direnci, süneklilik, darbe direnci vb.) özelliği ile bağlantılıdır. Tokluk enerji absorbsiyonu genel olarak iki farklı yöntemle ölçülmektedir. Bunlar EFNARC plaka eğilme deneyi ve yuvarlak plaka eğilme deneyleridir. Bu çalışmada püskürtme betonda ve diğer lifli betonlarda kullanılan plaka eğilme deneyleri ayrıntılı bir şekilde araştırılmış ve literatür çalışmaları incelenmişsir.

Anahtar kelimeler: Tokluk indeksi, EFNARC ve yuvarlak plaka eğilme testleri, Püskürtme beton

\section{Comparison of EFNARC and Round Plate Bending Test Methods Used in Measurement of Toughness Index}

\begin{abstract}
It is defined as the concrete made by spraying and consisting of aggregate, cement, water and some chemical additives transmitted with compressed air through the sprayed concrete pipeline, which is frequently used especially in the mining and construction industry. It is widely used in many areas such as underground engineering constructions, rock and ground support, coating and repair of structures, as it can be applied quickly without the need for reinforcement, can be shaped as desired and applied to any surface. In addition to these advantages, different amounts and structures of fiber can be easily added to the concrete. With the developing technology, the use of fiber in concrete has increased. The main reason for the use of fiber is its energy absorption feature. This property, which is also called toughness and expresses the area under the load-deflection curve, is related to the mechanical property (Crack resistance, ductility, impact resistance as.) of the material. Toughness energy absorption is generally measured by two different methods. These are the EFNARC plate bending test and the round plate bending test. In this study, plate bending tests used in sprayed concrete and other fiber concretes were investigated in detail and literature studies were examined.
\end{abstract}

Keywords: Toughness index, EFNARC and round determinate panel tests, Sprayed concrete

\section{Atıf için (Cite);}

Külekçi, G. (2021). Tokluk İndeksi Ölçümünde Kullanılan, EFNARC ve Yuvarlak Plaka Eğilme Deney Yöntemlerinin Karşılaştırılması, Recep Tayyip Erdoğan Üniversitesi Fen ve Mühendislik Bilimleri Dergisi, 2(2), 120-126. Doi: 10.53501/rteufemud.997776 


\section{Giriş}

Gerek inşaat sektöründe gerekse madencilik sektöründe yaşanan gelişmelere bağlı olarak lifli beton üretimi ve kullanımı artmıştır (Külekçi, 2019). Kullanılan lifli betonlar içerisinde en fazla kullanılanı ve dikkat çekeni püskürtme betondur. Püskürtme beton kuru ya da yaş olarak, basınçlı hava yardımı ile aynı ya da farklı boru yardımı ile agrega ve çimentonun belli bir açı ile yüzeye püskürtülmesi ile yapılan uygulamaya denir. Püskürtme betonda piriz hızlandırıcı ve benzeri katkılar kullanılabilir (Çakıroğlu vd., 2009; Külekçi, 2018a; 2018b). Püskürtme beton, kolay uygulanabilirliği, hızlı sertleşmesi ve beton özelliğini hızlı kazanması sayesinde birçok sektörde kullanımı artmıştır. Özellikle madencilik ve inşaat sektöründe yeraltı mühendislik yapılarında, baraj gövde ve şevlerinde, yol şevlerinde hasarlı binaların güçlendirilmesi ve onarılması gibi durumlarda sıklıkla kullanılmaktadır (Ayış, 2010; Çakıroğlu vd., 2009; Külekçi vd., 2015a; 2015b; Külekçi ve Çullu, 2021) (Şekil 1).

Betonda lif kullanımı birinci dünya savaşı ve sonrasındaki sanayi devrimi ile kullanılmaya başlanmıştır. Betonda donatı olarak kullanılan demirin yanında çelik ve farklı lif çeşitleri denenmiş ve bu konudaki çalışmalar günümüze kadar gelmiştir (Çakıroğlu vd., 2009; Külekçi, 2018b, 2021a; Külekçi ve Yılmaz, 2018; Galan vd., 2019). Günümüz de daha çok tahkimat elemanı olarak kullanılan püskürtme betonda sönümleme, tokluk, sıçrama, basınç ve çekme dayanımı üzerine birçok araştırma yapılmıştır (Hahn ve Holmgren, 1979; Homgren, 1993; Malmgren vd., 2005; Saiang vd., 2005). Yapılan bu araştırmalarda betonun çekme, darbe dayanımı, tokluk gibi özelliklerinin geliştirilmesi amacı ile beton içerisine farklı oran ve özellikte lif yapıları katılmıştır (Homgren, 1993; Çakıroğlu vd., 2009; Yun vd., 2015).

Betonda çekme dayanımının artırılmasına yönelik farklı lif yapılarının kullanılması 1900 lü y1llara dayanmaktadır (Yurdakul, 2001). Lif içeren yapılar, donatısız betondan farklı mekanik ve fiziksel özelliklere sahip bir yapı olduğu için sürekli ilave malzeme ve lif yapıları test edilmektedir. Günümüzde püskürtme beton içerisine farklı oranlarda ikame edilen lifler; çelik, plastik, cam ve sentetik malzemeden üretilmektedirler. Gelişen beton teknolojisi ile sentetik lif (polipropilen, polivinil alkol vb.) de püskürtme betonda yaygın olarak kullanılmaya başlamıştır (Hahn ve Holmgren, 1979; Homgren, 1993; Terzić vd., 2014; Zain, 2018). Üretilen lifli püskürtme betonların dayanımları Tablo 1'de verilmiştir.

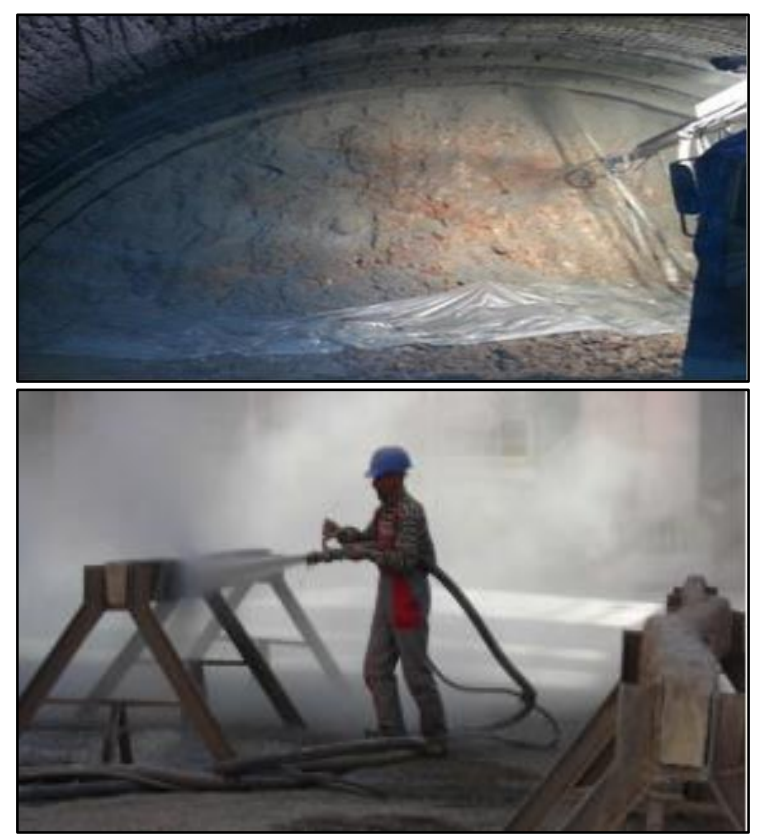

Şekil 1. Örnek püskürtme beton uygulamaları (Çakıroğlu vd., 2009; Külekçi vd., 2015)

Figure 1. Example shot-crete applications

Yeraltında ve yerüstünde uygulanan püskürtme beton dayanımını ölçmek için birçok deney yapılmaktadır. Enerji yutabilme kapasitesi lif katk1lı betonlarda aranan ve tokluk olarak da ifade edilen en önemli mekanik özelliklerdendir. Püskürtme betonda kullanılan liflerin miktarı, şekli ve narinliği arttıkça özgül kırılma enerjisi, dolayısı ile sünekliliği artırdığı belirtilmiş̧tir (Barros ve Cruz, 2001; Bernard, 2011; Bolat vd., 2014). Sünek davranışın artışı ise ilk çatlak sonrası yük taşıma kapasitesini artıracaktır. İlk çatlaktan kırılıncaya kadar sürecek olan enerji yutma kapasitesine tokluk denir. Bu tokluk değerinin ölçülmesi için çeşitli deneyler yapmışlardır. 
Tablo 1. Değişik lif tiplerinin mekanik özellikleri (Türk ve Kına, 2017)

Table 1. Mechanical properties of different fiber types

\begin{tabular}{lcccc}
\hline Lif Cinsi & $\begin{array}{c}\text { Çekme dayanım, } \\
(\mathrm{MPa})\end{array}$ & $\begin{array}{c}\text { Elastisite modülü, } \\
(\mathrm{GPa})\end{array}$ & $\begin{array}{c}\text { Maks. şekil } \\
\text { değiştirme, }(\%)\end{array}$ & $\begin{array}{c}\text { Yoğunluk } \\
\left(\text { ton/ } \mathrm{m}^{3}\right)\end{array}$ \\
\hline Çelik & $1100-2760$ & 200 & $0.5-35$ & 7.8 \\
Polipropilen & $552-759$ & 6.9 & 25 & 0.9 \\
Akrilik & $207-414$ & 8.3 & $25-45$ & 1.1 \\
Asbestler & $552-966$ & 4.1 & 0.6 & 3.2 \\
Pamuk & $414-690$ & 69 & $3-10$ & 1.5 \\
Cam & $1035-3795$ & 4.8 & $1.5-35$ & 2.5 \\
Naylon & $759-828$ & $83-138$ & $16-20$ & 1.1 \\
Polyester & $724-863$ & 2.1 & $11-13$ & 1.4 \\
Pamuk-Yün & $414-621$ & 3.5 & $10-25$ & 1.5 \\
\hline
\end{tabular}

Birçok araştırmac1 püskürtme betonda kullanılan değişik lifler ile bu liflerden değişik oranlarda kullanarak üç noktalı eğilme, basınç, çekme dayanımını gibi deneyleri yapmışlardır (Barros ve Cruz, 2001; Bolat vd., 2014; Grünewald ve Walraven, 2001; Nemkumar, vd., 1994). Yapılan araştırmalarda kullanılan liflerin narinlik oranlarının ve geometrilerinin de enerji yutma kapasitesini ve elastisite modülüne etkisi olduğu ortaya konmuştur (Galobardes vd., 2014; Nemkumar vd., 1994). Püskürtme betonda enerji yutma kapasitesinin ölçümü genel olarak plak eğilme deneyi ile ölçülmektedir (Hooton vd., 2001; Tunçdemir ve Güçlü, 2014).

\section{Materyal ve Metot}

Beton içerisine ikame edilen lifler betonun mekanik ve fiziksel özelliklerini tamamen değiştirmektedir. Bu özelliklerden en önemlisi tokluk olarak adlandırılan enerji yutabilme kapasitesidir. Betonun ilk kırılmaya başladığı çatlakla tamamen ayrılıncaya kadar geçen sürede ortaya çıkan gerilme grafiğinin altında kalan alana tokluk denir. Enerji yutma kapasitesi yani tokluk, gerilme grafiğinin (yüksehim eğrisi) altında kalan bölge ile anlatılır.

Püskürtme betonda enerji yutma kapasitesi genel olarak iki farklı yöntemle ölçülmektedir; EFNARC ve Yuvarlak plaka eğilme deneyi.

$\mathrm{Bu}$ plaka eğilme deneylerinde tokluk hesabı genel olarak ASTM C 1018 ve JSCE SF-4'e göre yapılmaktadır (ASTM C 1018, 1997; JSCE SF-4, 1984).

\section{Bulgular ve Tartışma}

Plak deneyleri birçok Avrupa ülkesinde püskürtme betonun enerji yutma kapasitesinin belirlenmesinde kullanılan bir yöntemdir. Genel olarak EFNARC yöntemi kullanılır bunun sebebi daha pratik olması ve net sonuçlar alınabilmesidir.

\subsection{EFNARC Plaka Eğilme Deneyi}

$\mathrm{Bu}$ deneyde, standart bir boyutta $(600 \times 600 \times 100 \mathrm{~mm})$ oluşturulan plaklar yükleme düzeneğine dört köşesinden serbestçe oturtulur. Oturtma işleminden sonra plak numunesi orta noktadan yükleme hızı 1 (mm/dak) olacak şekilde baskı uygulanır. Deneyde $25 \mathrm{~mm}$ 'lik plak ortası sehime kadar yutulan enerji esas alınmaktadır (ASTM C 1018, 1997) (Şekil 2).

Plak testi sonucunda elde edilen veriler ile Kuvvet-Sehim grafiği oluşturulur. Oluşturulan bu grafiğin altında kalan alan hesaplaması yapılarak Enerji-Sehim grafiği oluşturularak betonun tokluğu hakkında bilgi elde edilmiş olur (Şekil 3).

\subsection{Yuvarlak Plaka Eğilme Deneyi}

Yuvarlak plaka eğilme deney düzeneğinde isminden de anlaşılacağı üzere numuneler yuvarlak şekillidir. Yuvarlak şekilli deney numunesi $120^{\circ}$ 'lik açılarla konumlandırılmış 3 adet basit yapılı ayağın üzerine konulur 
(ASTM C 1018, 1997) (Şekil 4). Yapılan deneyde yuvarlak plaka üzerine uygulanan sabit yükleme hızıyla aksiyal yük altındaki numunenin odak noktasının (merkezinin) düşey yönde yer değiştirme miktarı hesaplanır. Deneyde devam eden yükleme sırasında oluşan çatlakların geometrik yapısı ve şekli incelenmelidir (Deng et al., 2016; Manca et al., 2018). Genellikle eğilme gerilmesi sonras1 genellikle $120^{\circ}$ açılarla bölünmüş 3 adet net şekilde görülen çatlak meydana gelir. Ortaya çıkan bu çatlaklar deney numunesinin sünek özellik gösterdiğinin kanıtıdır. Aksi durumda plak yükleme sonrasında merkez noktası çok az yer değiştirmiş ise kırılmada kayma gerilmesi oluşmuştur. Bu tür yenilme çok ani ve tahripkâr özellik taşır ve deneysel çalışmaların değerlendirilmesinde dikkate alınmalıdır (Arığlu vd., 2008; Deng vd., 2016).

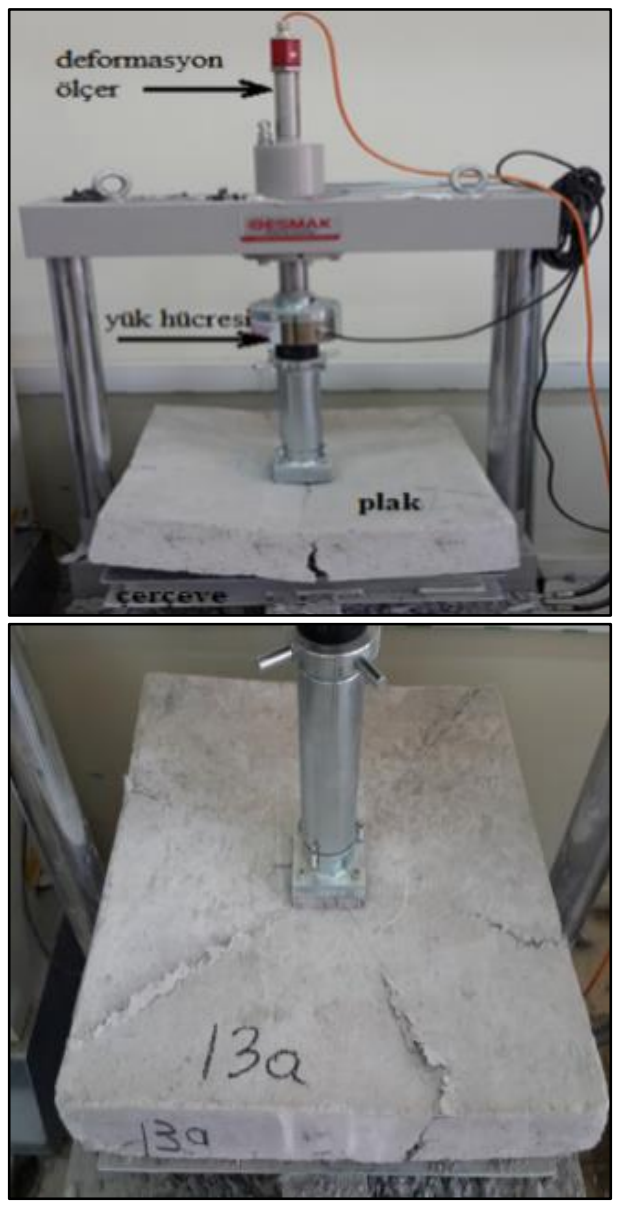

Şekil 2. EFNARC Plaka Eğilme Deney düzeneği (Bolat vd., 2014)

Figure 2. EFNARC Plate Flexural Test rig

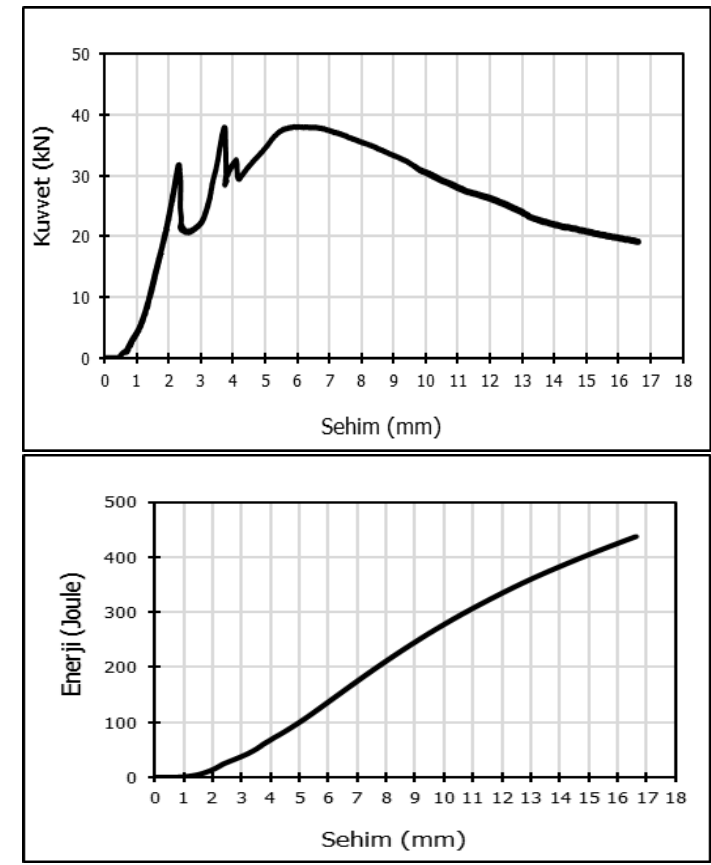

Şekil 3. Plak testinden elde edilen KuvvetSehim ve Enerji Sehim grafikleri (Külekçi, 2018b, 2019, 2021b)

Figure 3. Force-Deflection and EnergyDeflection plots from the plate test

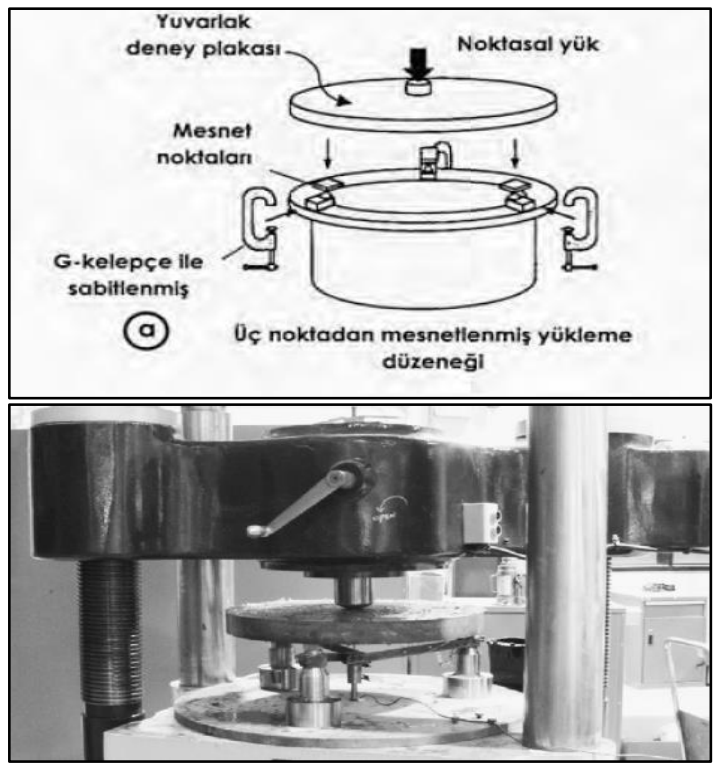

Şekil 4. Yuvarlak plak deney aleti ve çalışması (Arıoglu vd., 2008; Deng vd., 2016)

Figure 4. Round plate tester and its operation

Yuvarlak plak örneklerinin kalınlıklarının tokluğuna etkisi üzerine etkisini inceleyen Ciancio vd. (2016) emilen enerjinin kalınlığa bağlı olduğunu gösteren deneysel bir çalışma 
yapmış ve Sonuçların doğrulanması için, absorbe edilen enerji ile malzeme kırılma enerjisi arasında doğrudan bir ilişkki sağlayabilecek basit bir analitik model geliştirmiştir. Sonuç olarak, mini bulutlu RDP testiyle birlikte klasik tasarım araçlarının kullanılmasına olanak tanıyan yeni bir tasarım prosedürü önermiştir ve analitik modelde tanitilan hipotez hem deneysel hem de doğrusal olmayan bir sayısal model vasıtasıyla doğrulamıştır (Şekil 5).

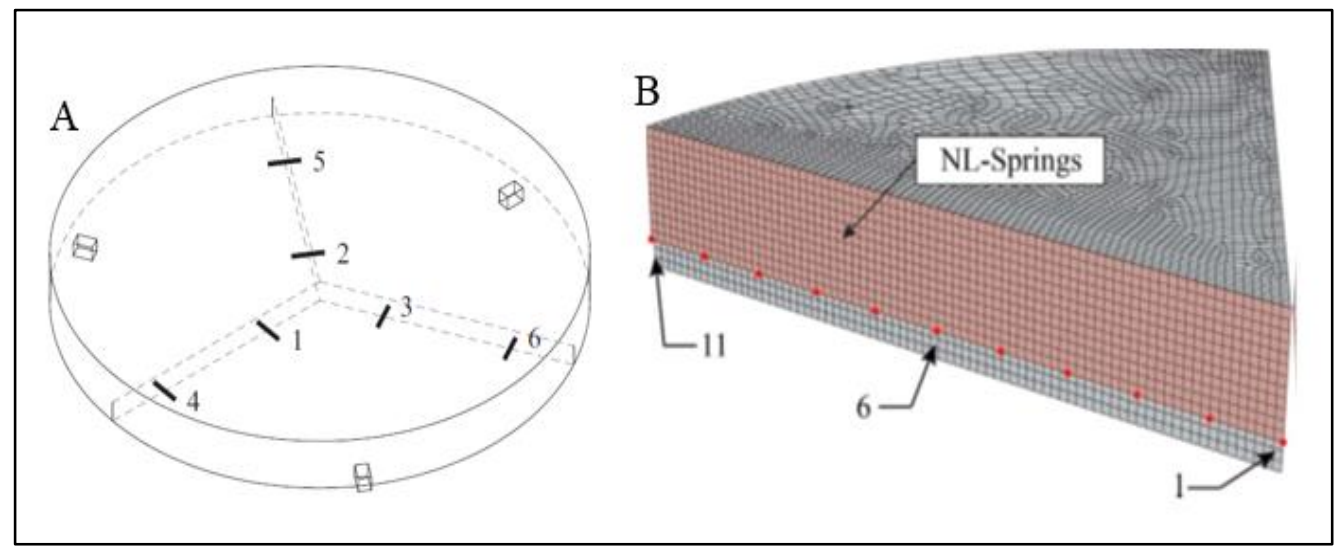

Şekil 5. a) Yuvarlak plak örneklerinin şematik 3 radyal çentiklerini, desteklerin ve klips göstergelerinin konumunu göstermektedir. b) Sonlu eleman örgüsü: Kırmızı alan, dügümm noktalarında doğrusal olmayan (NL) yaylar kullanılarak simüle edilen çatlak yüzeyini belirtir (Ciancio vd., 2016).

Figure 5. a) Schematic 3 radial notches of round plate specimens, location of supports and clip indicators b) Finite element lattice: Red area indicates crack surface simulated using non-linear $(N L)$ arcs at nodal points

Betonun iki eksenli gerilme mukavemeti için araştırmacilar yuvarlak plak deneyinde farklı öneriler sunmuşlardır. Numune geometrisi, uygun şekilde işlenmesi ve destek koşulları önermişlerdir (Nour vd., 2011; Kim vd., 2013). Yazarlar destek noktalarının kırılma açısı üzerindeki etkisini inceleyerek yük dağılım modellemesi yapmaya çalışmışlardır (Şekil 6).

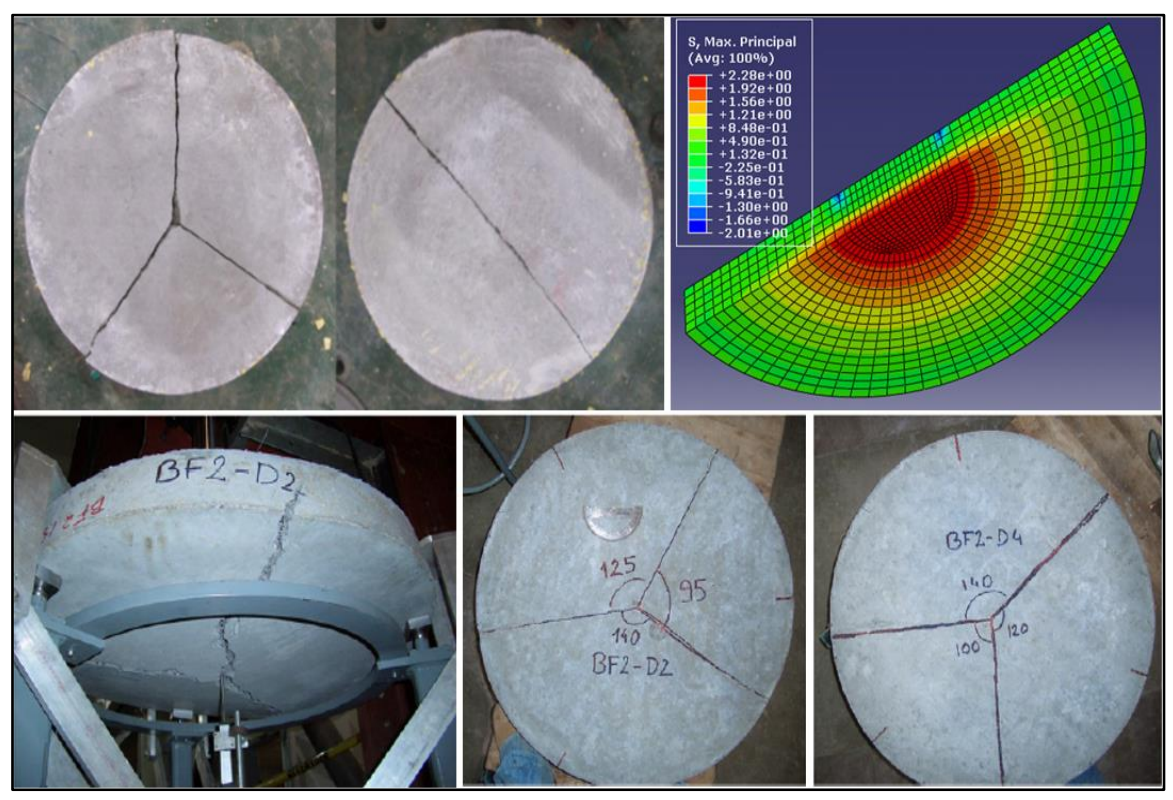

Şekil 6. Yuvarlak panelleri için test düzeneği, tipik arıza mekanizmaları ve yük dağılım modellemesi (Nour vd., 2011; Kim vd., 2013).

Figure 6. Test setup for round panels, typical failure mechanisms and load distribution modeling 


\section{Sonuçlar}

Yapılan çalışmada, lifli betonlarda kullanılan plaka eğilme deneyleri incelenmiştir. İnceleme sonucunda,

Lifli beton yapılarında statik davranışın ölçülmesi için kiriş yerine "plaka" olarak modellenmesi daha doğru olacağ 1 ,

Lifli yapıların bekletilme süreleri (kür süresi) ve beton içerisindeki lif miktarı arttıkça plakanın yuttuğu enerji miktarının da $\operatorname{arttığı}$. $\mathrm{Bu}$ durum püskürtme betonun kullanım alanlarında, betondan beklenen mekanik dayanım açısından önemli olduğu, EFNARC Plaka Eğilme Deneyi ile plaklardaki enerji yutma kapasiteleri açıç̧a ortaya konulabileceği,

Betonun tokluk değerinin belirlenmesinde diğer bir yöntem olan yuvarlak plaka eğilme deneyi ile beton örneklerin absorbe ettiği enerjinin de belirlenebileceği, fakat dikkat edilmesi gereken husus numunelerin geometrisi, numunenin uygun şekilde işlenmesi ve beton örneğin deney sırasında uygulanacak destek koşullarına dikkat edilmesi olduğu,

Yapılan çalışmalarda destek noktalarının kırılma açısı üzerinde etkisinin olduğunu sonuçlarına varılmıştır.

\section{Kaynaklar}

Arıoğlu, E., Yüksel, A., Yılmaz, A.O. (2008). Püskürtme Beton Bilgi Föyleri-Çözümlü Problemler. TMMOB Maden Müh. Odası İstanbul Şubesi.

ASTM C 1018. (1997). Standart Test Method for Flexural Toughness and First-Crack Strength of Fiber-Reinforced Concrete.

Ayış, H.İ. (2010). Tünel Açma Sistemlerinde Çelik Lifli Püskürtme Betonun Uygulanabilirliği, Yüksek Lisans Tezi, Yıldız Teknik Üniversitesi, Fen Bilimleri Enstitüsü, Türkiye.

Barros, J.A.O., Cruz, J.S. (2001). Fracture energy of steel fiber-reinforced concrete. Mechanics of Advanced Materials and Structures, 8, 29-45.

Bernard, E.S. (2011). Influence of geometric factors on the punching load resistance of early-age fibre reinforced shotcrete linings. Tunnelling and Underground Space Technology, 26(4), 541-547.

Bolat, H., Şimşek, O., Çullu, M., Durmuş, G., Can, Ö. (2014). The effects of macro synthetic fiber reinforcement use on physical and mechanical properties of concrete. Composites Part B: Engineering, 61, 191-198.

Ciancio, D., Manca, M., Buratti, N., Mazzotti, C. (2016). Structural and material properties of mini notched round determinate panels. Construction and Building Materials, 113, 395403.

Çakıroğlu, A.M., Serdal, T., Çakıroğlu, M.G. (2009). Püskürtme betonda görülen problemler problemler. Yapı Teknolojileri Elektronik Dergisi, 5(2), 43-49.

Deng, Z., Shi, F., Yin, S., Tuladhar, R. (2016). Characterisation of macro polyolefin fibre reinforcement in concrete through round determinate panel test. Construction and Building Materials, 121, 229-235.

Galan, I., Baldermann, A., Kusterle, W., Dietzel, M., Mittermayr, F. (2019). Durability of shotcrete for underground support-review and update. Construction and Building Materials, 202, 465-493.

Galobardes, I., Cavalaro, S.H., Aguado, A., Garcia, T. (2014). Estimation of the modulus of elasticity for sprayed concrete. Construction and Building Materials, 53, 48-58.

Grünewald, S., Walraven, J.C. (2001). Parameterstudy on the influence of steel fibers and coarse aggregate content on the fresh properties of selfcompacting concrete. Cement and Concrete Research, 31(12), 1793-1798.

Hahn, T., Holmgren, J. (1979). Adhesion of shotcrete to various types of rock surfaces. 4th ISRM Congress, Montreux, Switzerland, September 1979.

Homgren, J. (1993). The use of yield line theory in the design of steel fiber reinforced concrete slabs. Shotcrete for Underground Support IV Proceeding of Engineering Foundation Conference.

Hooton, R., Bernard, E., Pircher, M. (2001). The influence of thickness on performance of fiberreinforced concrete in a round determinate panel test. Cement, Concrete and Aggregates, 23, 27.

JSCE SF-4. (1984). Standards For Tests Methods of Fiber Reinforced Concrete, Japan Concrete Institute.

Kim, J., Kim, D.J., Zi, G. (2013). Improvement of 
the biaxial flexure test method for concrete. Cement and Concrete Composites, 37, 154-160.

Külekçi, G. (2018a). Effect of DifJerent Synthetic Fiber Using Shotcrete on Ultrasonic Pulse Velocity. The 4th International Underground Excavations Symposium, 493-499.

Külekçi, G. (2018b). Investigation of the Utilization Areas of Construction and Demolition Wastes in the Black Sea Region Instead of Aggregate and Their Areas of Usage in the Mining Industry, PhD Dissertation, Karadeniz Tecnical Universty, Graduate Institute of Natural and Applied Sciences, Turkey.

Külekçi, G. (2019). Energy absorption measurement in shotcrete by EFNARC plaque deflection experiment. 3rd International Conference on Advanced Engineering Technologies, September, 505-508.

Külekçi, G. (2021a). Comparison of field and laboratory result of fiber reinforced shotcrete application. Periodica Polytechnica Civil Engineering, 65(2), 463-473.

Külekçi, G. (2021b). Investigation of fly ash added light concretes with respect to gamma radiation transmission properties of $133 \mathrm{Ba}$ and $137 \mathrm{Cs}$. Radiation Effects and Defects in Solids, 1-12.

Külekçi, G., Çullu, M. (2021). The investigation of mechanical properties of polypropylene fiberreinforced composites produced with the use of alternative wastes. Journal of Polytechnic, 24(3), 1171-1180.

Külekçi, G., Kesimal, A., Yılmaz, T., Deniz, A. (2015a). Investigation of shotcrete support in gümüşhane mastra gold mine. 7. Ulusal Kırmataş Sempozyurnu, 221-229.

Külekçi, G., Yılmaz, A. O. (2018). Classification of rock and support applications far tunneling, sample of environmental road in Gümüşhane. Tbe 4th International Underground Excavatıons Symposium, 535-540.

Külekçi, G., Yılmaz, A. O., Yılmaz, T., Özyazıcı, B. (2015b). Exeavation and reinforcement applications in Trabzon Akyazı tunnel. IMCET2015, 529-540. Antalya.

Malmgren, L., Nordlund, E., Rolund, S. (2005). Adhesion strength and shrinkage of shotcrete. Tunnelling and Underground Space Technology, 20(1), 33-48.

Manca, M., Karrech, A., Dight, P., Ciancio, D.
(2018). Image processing and machine learning to investigate fibre distribution on fibrereinforced shotcrete round determinate panels. Construction and Building Materials, 190, 870880.

Nemkumar, B., Jean-Francois, T., Denis, B., David, W. (1994). Steel fiber reinforced wet-mix shotcrete: influence of diber geometry. Concrete International:Design and Construction, 16(6), 27-32.

Nour, A., Massicotte, B., De Montaignac, R., Charron, J.P. (2011). Derivation of a crack opening deflection relationship for fibre reinforced concrete panels using a stochastic model: Application for predicting the flexural behaviour of round panels using stress crack opening diagrams. Cement and Concrete Research, 41(9), 964-974.

Saiang, D., Malmgren, L., Nordlund, E. (2005). Laboratory tests on shotcrete-rock joints in direct shear, tension and compression. Rock Mechanics and Rock Engineering, 38, 275-297.

Terzić, A., Andrić, L., Mitić, V. (2014). Mechanically activated coal ash as refractory bauxite shotcrete microfiller: Thermal interactions mechanism investigation. Ceramics International, 40(8A), 12055-12065.

Tunçdemir, H., Güçlü, E. (2014). Post crack behavior of shotcrete in rock support interaction curve. Selcuk University Journal of Engineering, Science and Technology, 2(2), 3131 .

Türk, K., Kına, C. (2017). The use of hybrid in cementitious composites. Pamukkale University Journal of Engineering Sciences, 23(6), 671678.

Yun, K.K., Choi, S.Y., Yeon, J. H. (2015). Effects of admixtures on the rheological properties of high-performance wet-mix shotcrete mixtures. Construction and Building Materials, 78, 194202.

Yurdakul, Ş. (2001). Püskürtme Beton Teknolojisinin TTK Ocaklarl Ana Galerilerinde Uygulanabilirliğinin Araştırılması. Zonguldak Karaelmas Üniversitesi.

Zain, N.E.L. (2018). An Experimental Study of the Validity of the Round Panel Test Method for Shotcrete, MSc Thesis, KTH Royal Institute of Technology, School of Architecture and The Built Environment, Sweden. 